\title{
EMTP Based Stability Analysis of Space Station Electric Power System in a Test Bed Environment
}

Narayan V. Dravid

National Aeronautics and Space Administration

Lewis Research Center

Cleveland, Ohio

Thomas J. Kacpura

Lewis Research Center Group

Sverdrup Technology, Inc.

Brook Park, Ohio

and

Andrew M. O'Connor

Analytical Engineering Corporation

North Olmsted, Ohio

August 1992

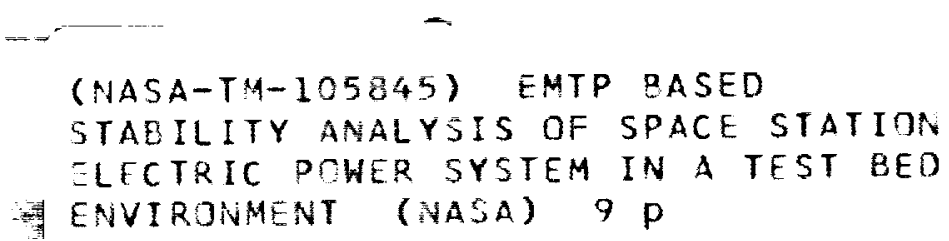

$N 93-15503$ 


\section{EMTP BASED STABILITY ANALYSIS OF SPACE STATION ELECTRIC POWER SYSTEM IN A TEST BED ENVIRONMENT}

\author{
Narayan V. Dravid \\ National Aeronautics and \\ Space Administration \\ Lewis Research Center \\ Cleveland, Ohio 44135
}

\author{
Thomas J. Kacpura \\ Sverdrup Technology, Inc. \\ Lewis Research Center Group \\ Brook Park, Ohio 44142
}

\author{
Andrew M. O'Connor \\ Analytical Engineering Corp. \\ North Olmsted, Ohio $\mathbf{4 4 0 7 0}$
}

\begin{abstract}
The Space Station Freedom Electric Power System (EPS) will convert solar energy into electric energy and distribute the same using an 'all dc', Power Management and Distribution (PMAD) System. Power conditioning devices (dc to dc converters) are needed to interconnect parts of this system operating at different nominal voltage levels. Operation of such devices could generate under damped oscillations (instability) under certain conditions. Criteria for instability are examined and verified for a single device. Suggested extension of the criteria to a system operation is examined by using the EMTP model of the PMAD DC test bed. Wherever possible, data from the test bed is compared with the modeling results.
\end{abstract}

\section{INTRODUCTION}

NASA-Lewis Research Center has the responsibility to oversee the design, fabrlcation, and assembly of the Electric Power System (EPS) for the Space Station Freedom (SSF). As per the current design, the EPS shall be an 'all dc' system with a primary part operating at $160 \mathrm{~V}$ (nominal) and a secondary part operating at $120 \mathrm{~V}$ (nominal). The loads, which operate at various voltage levels, will be supplied from the secondary. Clearly, voltage conversion must take place when connecting different parts of the system. The conversion devices are typlcally power electronic devices and are known to exhibit unstable operation (under damped oscillations) under certain conditions. Criteria have been established for stable operation of the individual devices. This paper will analyze these criteria and study possible extension of the same to system level operation.

The PMAD DC test bed was set up at NASA LeRC to help with the SSF EPS related task. A computer model of the test bed system was also developed, using EMTP as the simulation package, to support the test bed operation [1 ]. This model will be used to verify conclusions of the proposed analysis.

\section{THE INSTABILITY PROBLEM}

Typically, a power (or voltage) converter consists of energy storage elements, inductors and capacitors, being switched at a high frequency (10 $\mathrm{kHz}$ and above). Such a switching action generates high frequency noise, consequently needing filters at both the input and the output ends of the converter. As will be shown later the filters themselves could give rise to under damped oscillations.

CAUSES OF INSTABILITY - When a power converter operates under a constant output voltage regime (using feedback control) it behaves as a constant power type load (with negative Incremental resistance) to its source. A tuned circuit, such as an Input filter, combined with the negative input resistance of the converter could generate under damped oscillations.

STABILITY CRITERIA - For power converters as described above stability criteria (aka Middlebrook Stability Criteria) have been established [2]. Simply stated: For stable operation, the magnitude of the output impedance of the converter input filter (source) should be very small compared to the magnitude of the input impedance of the converter (load) when operating in open loop feedback condition. It should be noted here that the criteria evolved as part of the design process of Input filters for the converter devices. While no mention is made of the phase angles of the respective impedances it is implied that the net phase angle of the two paralleled impedances lies within + and -90 deg.

A MODIFIED CRITERION - If the criterion is modified such that only real parts of the respective 
admittances, l.e., the conductances, are compared, then, for stability, the output conductance of the input filter should be greater than the input conductance of the converter. This modification stems from the fact that only the presence of a negative real part contributes to instability because it introduces negative damping.. If the sum of the source and the load conductances yields a positive number, in a specified frequency range, then stability is assured. This also implies that the phase angle lies between + or -90 deg; the actual value does not matter The modified criterion will be applied in the present analysis to ascertain the stability of a converter under different operating configurations.

METHODS TO REDUCE INSTABILITY - For a single converter the best method to reduce instability is to optimally design the complete converter (Including filters). When the negative input impedance of the converter is insufficiently neutralized by a passive, lossy network connected at its input, e.g., the input filter, underdamped oscillations could result due to ordinary loading disturbances. Therefore, the input filter should be designed with the proper amount of damping to balance the need for stability against that of filtering.

STABILITY IN THE SYSTEM CONTEXT - An otherwise stable converter (including the input filter), when connected to a power system will certainly see a different system (source) output conductance. Because a typical system consists of a lossy, passive network, it is reasonable to assume that the source conductance will be higher than before, thereby assuring stability. Of course, there are other converters connected to the system network; but these are connected through thelr respective, properly tuned and damped, filters in addition to some lossy network elements. There are two situations where two converters are very close to each other (electrically speaking) leading to the possibility of insufficient source conductance and, hence, instability. They are: two DDCUs connected to the MBSU bus and three BCDUs connected to the DCSU bus. Any stability problem in this context will be uncovered because such configurations are included in the analysis.

\section{TEST BED MODEL FOR STABILITY ANALYSIS}

The EMTP test bed model has already been developed in connection with the test bed operation. A configuration of this model, also known as the Channel $A$ test bed configuration and shown in Figure 1, was used for the present study. While other configurations could be used, the selected one is presently the closest to that of the test bed.

IMPEDANCE MEASUREMENT TECHNIQUE The Impedance at any point in the network is calculated as the ratio of an ac voltage component and the corresponding current component. There are different methods of creating the ac components in an otherwise dc system. One such method is described in [3]. In the model, a current is injected at the point in question using an ideal ac current source as shown in Flgure 2. This injection creates an ac voltage at that point and corresponding current components in the 'source' and 'load' directions. The ideal current source has infinite impedance and, therefore, does not load or affect the original network in any manner. Thus, both the 'source' and the 'load' impedances can be measured (calculated) at the same time. Frequency of the applied ac current source is varled to obtain the impedance as a function of frequency. Measuring the conductance requires only mathematical manipulation.

Converter Input Conductance Measurement - A slightly different approach is needed to measure the converter input conductance using the functional EMTP model. Since the converter model has a controlled current source at its input (see Figure 3), the current into the converter can not be modulated by an external current source as in Figure 2. Instead, a variable frequency voltage source is connected in series with the converter input filter (on the input side) to create a voltage perturbation and a corresponding current perturbation at the converter input. These two quantities can then be used, as before, to compute the conductance

Using the technique just described, the converter input conductance was determined to be 0.27 mhos. Also, since the phase angle difference of the current and voltage waveforms was $180 \mathrm{deg}$ the conductance will be a negative quantity. This conductance can also be analytically determined from the expression $g=d l / d V=-P /\left(V^{\star} V\right)$, where $g$ is the conductance, $I$ is the converter input current, $P$ is the converter load, and $V$ is the applied voltage at the converter input. This expression is derlved by modeling the converter as a constant power load at its input terminals.

Measurement Verification - The impedance measurement at the input filter of a DDCUdc to dc converter was modeled using EMTP and the results were verified by comparison with test data as shown in Figure 4. This verification was limited 


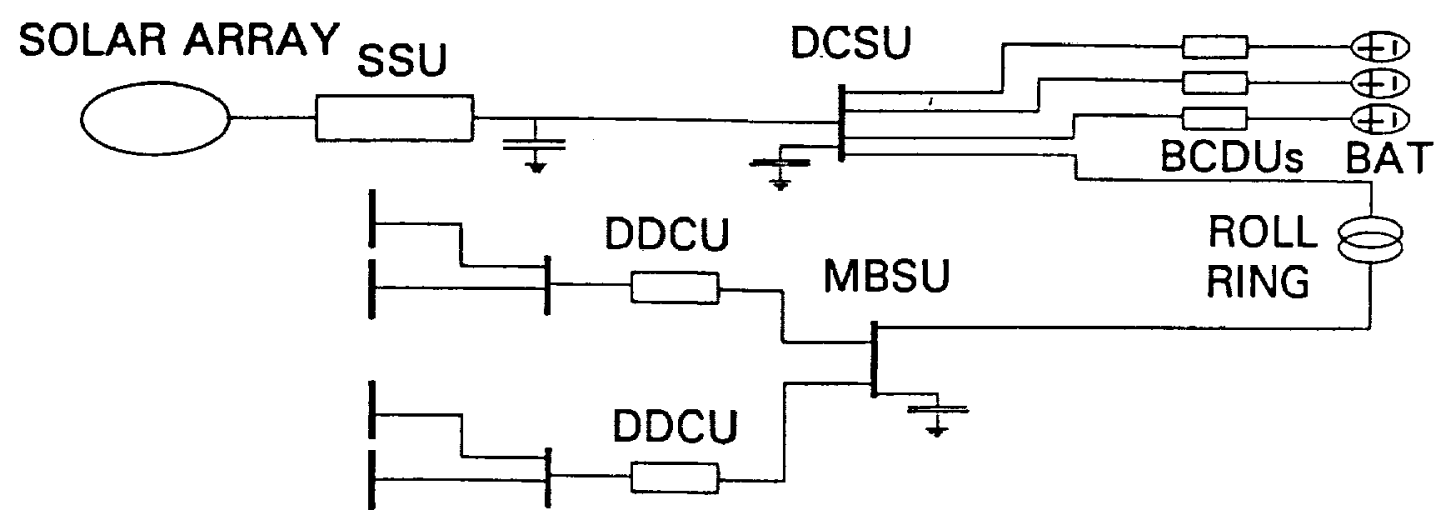

FIGURE 1 - EMTP MODEL OF THE DC PMAD TEST BED

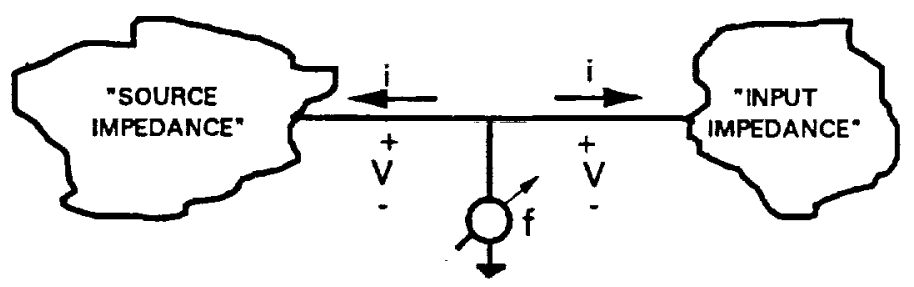

FIGURE 2 - IMPEDANCE MEASURING SETUP FOR EMTP

DAMPING RESISTOR

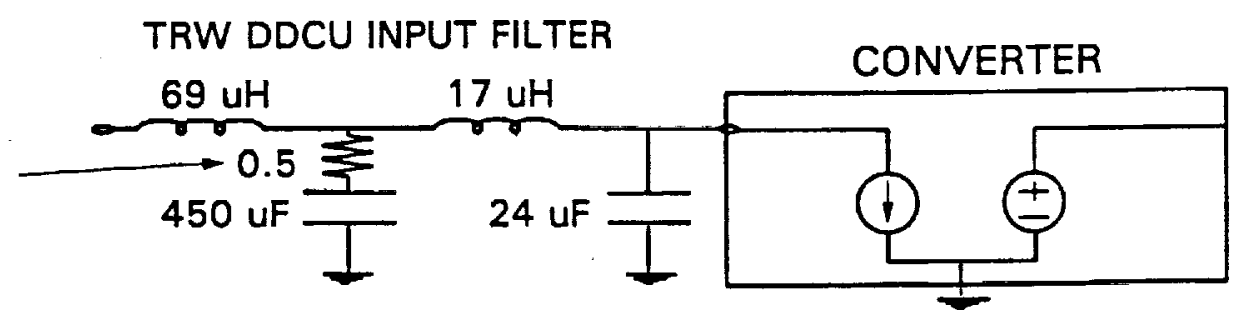

FIGURE 3 - TRW 6.25 KW DDCU MODEL WITH INPUT FILTER

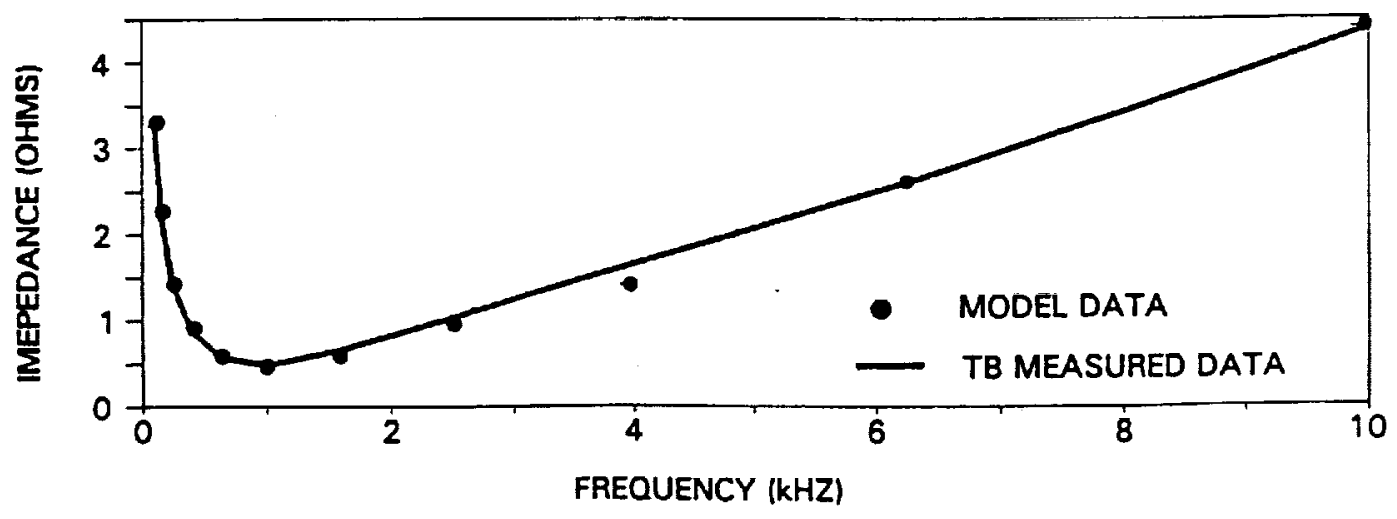

FIGURE 4 - TRW DDCU INPUT IMPEDANCE COMPARISON OF MODEL \& MEASURED DATA 
to impedance magnitudes only as EMTP does not permit phase angle measurement, conveniently. Initially EMTP was selected for both, large signal analysis (transient response) and small signal analysis (conductance measurement). Later it was decided to use SABER[4], a circult simulation software package, for the small signal analysis. Thus, all of the transient response results are from EMTP while the conductance measurement results are from SABER.

\section{SIMULATION RESULTS}

In addition to the Impedance measurement verification tests performed as described earlier, simulations were performed to study the application of the criterion for three situations: 1) the DDCU by itself, 2) the DDCU connected as a load in the test bed system during insolation, and 3) the DDCU as a load during eclipse. Each situation was divided in two parts: a) with normal value (l.e., $0.5 \mathrm{ohms}$ ) of damping resistance in the DDCU input filter, and $b$ ) the damping resistance reduced to 0.05 ohms. (Here, it should be noted that the value of damping resistance could not be reduced unth after the steady state was reached following a startup.) Thus, there were six cases in all. For each case, first the sum of the output conductance of the DDCU input filter and the converter input conductance $(-0.27$ mhos) was obtained for the frequency range of $100 \mathrm{~Hz}$ to $10 \mathrm{kHz}$, using SABER. This is plotted in part 'A' of figures 5 through 10 . (For the purposes of the next section, this quantity will be called the bus conductance at the DDCU internal bus or simply the DDCU bus conductance.) Secondly, for each case, a transient response of the input current at the DDCU input filter is obtained for a $50 \%$ load drop at the DDCU output, using EMTP. This is plotted in part ' $B$ ' of figures 5 through 10 . The system model for the SABER simulation consists mostly of the primary system network, including the input filters of all of the connected converters. Voltage or current sources were used beyond the filters, appropriately. Again, the six cases are as follows.

CASE 1: A single DDCU supplied by a voltage source at the input filter, supplying rated load:; normal damping used.; see Figures $5 \mathrm{~A}$ and $5 \mathrm{~B}$.

CASE 2: same as CASE 1 except that the damping resistance in the DDCU filter reduced to 0.05 ohms; see Figures $6 \mathrm{~A}$ and $6 \mathrm{~B}$.

CASE 3: SSU feeding the DDCU loads and charging the batteries; normal damping in DDCU input filter; see Figures $7 \mathrm{~A}$ and $7 \mathrm{~B}$.
CASE 4: same as case 3 with damping resistance reduced in the DDCU input filter; see Figures $8 \mathrm{~A}$ and $8 \mathrm{~B}$.

CASE 5: Eclipse mode operation with batteries feeding the DDCU loads; normal damping in DDCU filter; see Figures $9 A$ and $9 B$.

CASE 6: same as CASE 5 with damping resistance reduced in the DDCU input filter; see Figures $10 \mathrm{~A}$ and $10 \mathrm{~B}$.

\section{DISCUSSION OF RESULTS}

At the outset one should note that the test bed EPS is an inherently stable system when operated as designed. Thus, in the model, it was necessary to deviate from the designed value of damping resistance to create some level of instability. There may be other ways to generate instability but that area was not explored.

FREQUENCY RANGE OF INTEREST - Although all of the SABER plots extend up to $10 \mathrm{kHz}$, the range of frequency of interest for the purposes of this analysis extends only up to about $1 \mathrm{kHz}$. There are two reasons for that. First of all, the bandwidth of the converter controller is about $1 \mathrm{kHz}$. Therefore, the assumption of constant power load, which depends upon perfect output voltage regulation, is valid only up to that region of frequency. Secondly, a limitation exists in the plotting program which does not permit detection of any frequency greater than $5 \mathrm{kHz}$. Thus, although the resonant frequency of the second stage of the input filter is of the order of $8 \mathrm{kHz}$, it cannot be seen on the plots.

Figure 5A shows the bus conductance as a functlon of frequency and its value is negative upto about $350 \mathrm{~Hz}$. However, in Figure $5 \mathrm{~B}$ there is no sign of any unstable operation. This is because the only mode of oscillation is in the input filter at about $1 \mathrm{kHz}$. The bus conductance is quite positive around that frequency. Figures $6 \mathrm{~A}$ and $6 \mathrm{~B}$ show the results when filter damping is reduced. The bus conductance value in now only slightly positive at the oscillation frequency and results in the oscillation in the transient response. Clearly, the filter is now sharply tuned (high $Q$ ) and the behavlor is appropriate.

Figure 7A shows the DDCU bus conductance variation when under typical 'insolation' operating condition. Upto $1 \mathrm{kHz}$ the conductance value is quite high pointing to a stable operation. This conclusion is borne out by the transient response of Figure 7B. Figures $8 \mathrm{~A}$ and $8 \mathrm{~B}$ show results the when the DDCU input filter damping is reduced. The bus conductance appears to have the lowest value in the vicinity of $1 \mathrm{kHz}$, which is also the 


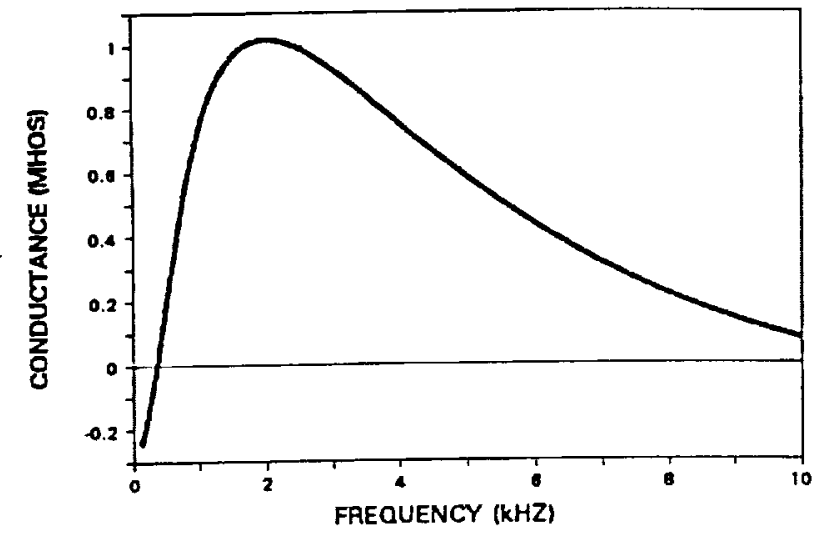

FIGURE 5A - CONDUCTANCE VS FREQUENCY $R=0.5$ OHMS, SOURCE AT INPUT

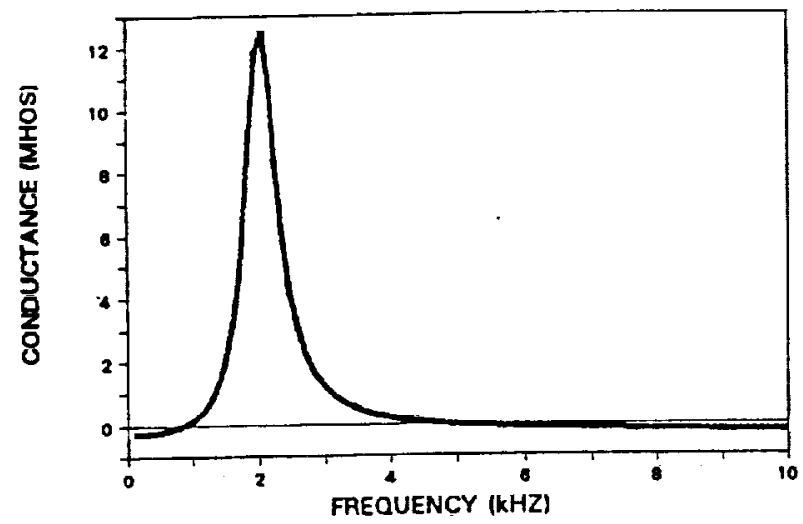

FIGURE 6A - CONDUCTANCE VS FREQUENCY $R=0.05$ OHMS, SOURCE AT INPUT

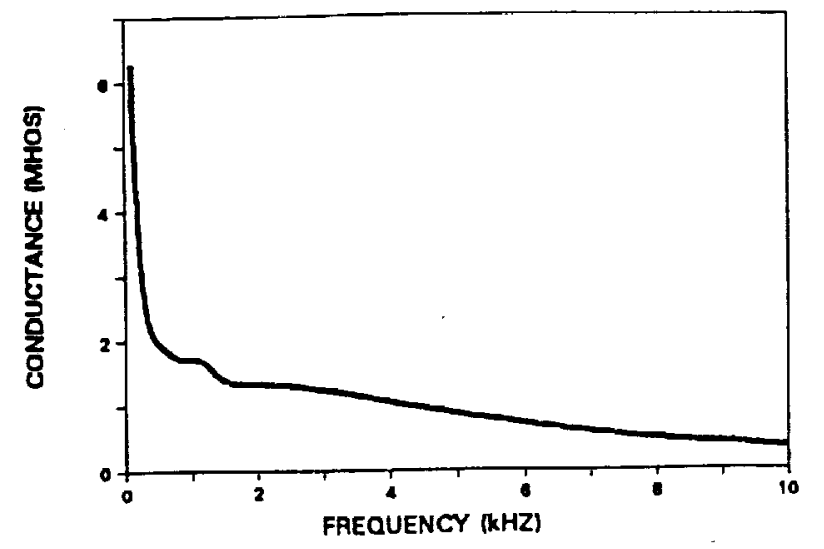

FIGURE 7A - CONDUCTANCE VS FREQUENCY 5 $R=0.5$ OHMS, SA \& SSU SOURCE

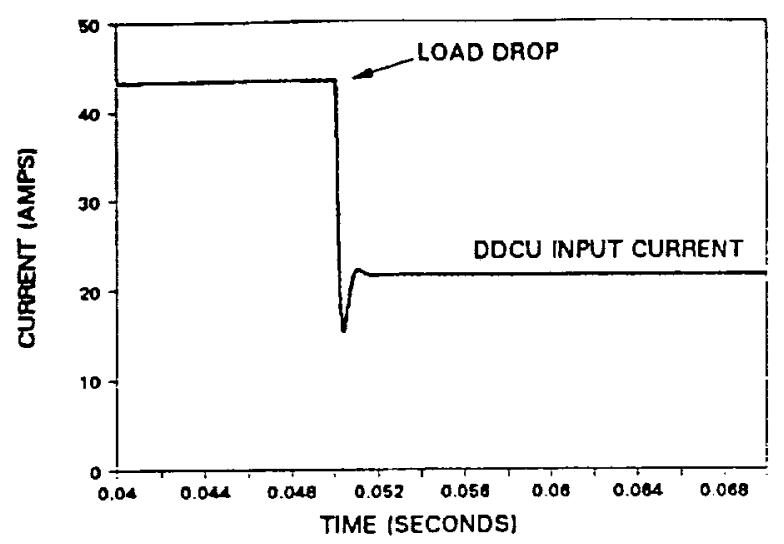

FIGURE 5B - DDCU 50\% LOAD DROP $R=0.5$ OHMS, SOURCE AT INPUT

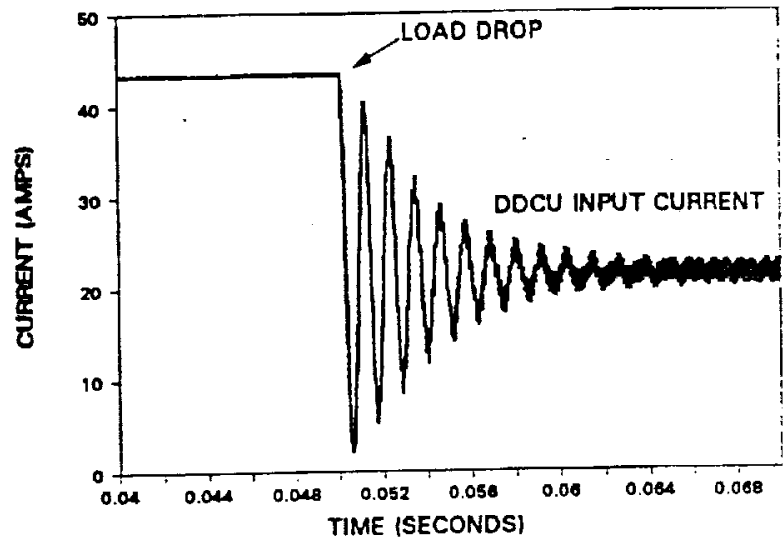

FIGURE 6B - DDCU 50\% LOAD DROP $\mathrm{R}=0.05$ OHMS, SOURCE AT INPUT

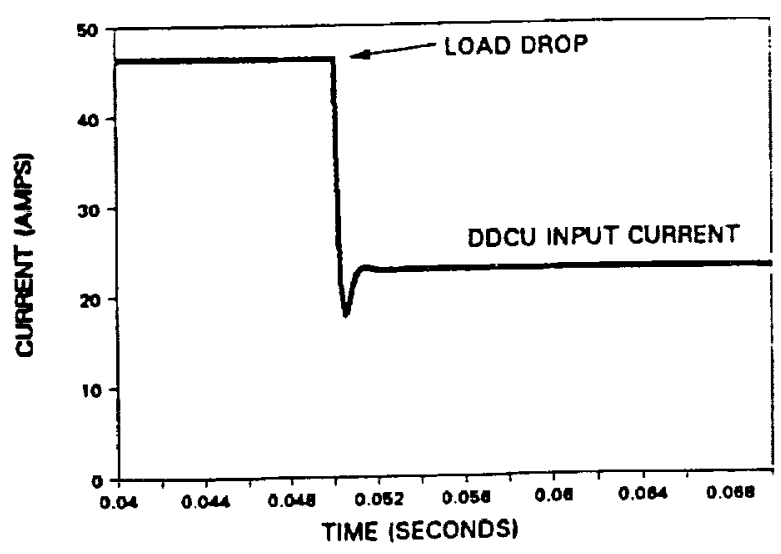

FIGURE $7 B$ - DDCU 50\% LOAD DROP $R=0.5$ OHMS, SA \& SSU SOURCE 
frequency of oscillation in the transient response.

Figure 9A shows the DDCU bus conductance variation while operating under 'eclipse' condition. The smallest value, one again, is near $1 \mathrm{kHz}$ but positive and high enough to give a stable transient behavior as indicated by Figure 9B. Figures 10A and $10 \mathrm{~B}$ show results for reduced filter damping. The bus conductance value is still the smallest around $1 \mathrm{kHz}$ but is substantially smaller and we see the corresponding oscillations in Figure 10B.

In cases 3 through 6 , two DDCUs were connected at the MBSU bus and three BCDUs were connected at the DCSU bus. The results of these cases do not suggest any stability problem even for cases 4 and 6 where the DDCU input filter damping was reduced. Based on these results it appears that any converter interactions, which could possibly cause instability, are absent when a properly tuned converter is connected to a typical system network. It is quite possible, however, that such interactions may take place when more than one converter is in a reduced damping mode. Of course, that is not a normal mode of operation.

\section{FUTURE WORK}

The analysis work will continue to determine if use of higher fidelity models, both for the converters in EMTP and for the system network in SABER would yield substantially different but consistent results. Thus, the following would be explored.

Use the higher fidelity EMTP based circuit model of the DDCU

Increase the fidelity of the SABER converter models beyond the input filter.
Modify the EMTP plotting program to handle frequencies upto $10 \mathrm{kHz}$.

Modity the DDCU input filler resistance in the hardware to validate the model behavior.

\section{CONCLUSIONS}

A modification of the well known Middlebrook stability criterlon is presented based on relationships of 'source' and 'load' conductances at the interface of a regulated converter. Using the example of the PMAD DC test bed at NASA Lewis, the modified criterion is applied and verified by obtaining corresponding translent response. For the specific test bed system, it is observed that there will be no stability problem when properly designed hardware is employed. Work will continue to apply the criterion to a higher fidelity model to see if results obtained from the approximate system model would still be valid.

\section{REFERENCES}

[1] N. V. Dravid, T. J. Kacpura, and K-S Tam, "An EMTP System Level Model of the PMAD DC Test Bed" IECEC-91, August 4-9, 1991, Boston, MA.

[2] A. D. Middlebrook, and S. C'uk, "Advances in Switched Mode Power Conversion ", Power Electronic Series, Vol. I, pp 91-107, TESLAco Pasadena, CA.

[3] R. M. Button, A. S. Brush, "Stabllity Testing and Analysis of a PMAD DC Test Bed for the Space Station Freedom", IECEC-92, August 2-7, 1992, San Diego, CA,

[4] Analogy, Inc., P. O. Box 1669, Beaverton, OR, 97075-1669. 


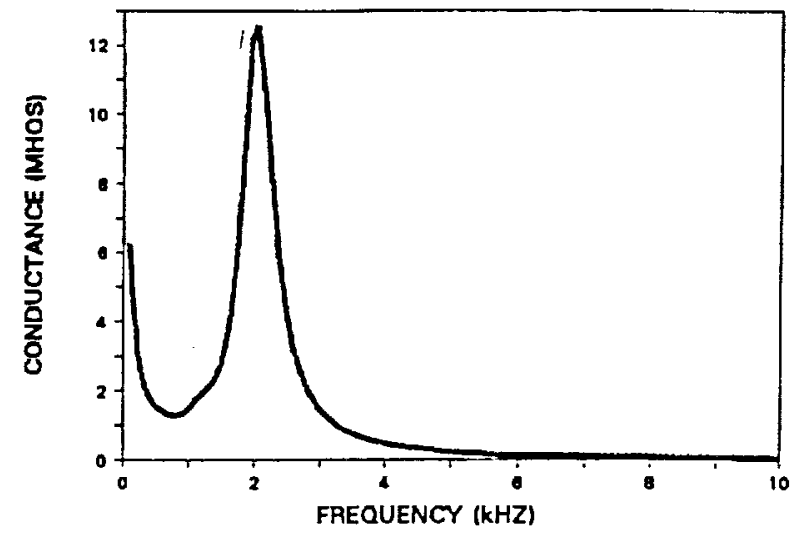

FIGURE 8A - CONDUCTANCE VS FREQUENCY $R=0.05$ OHMS, SA \& SSU SOURCE

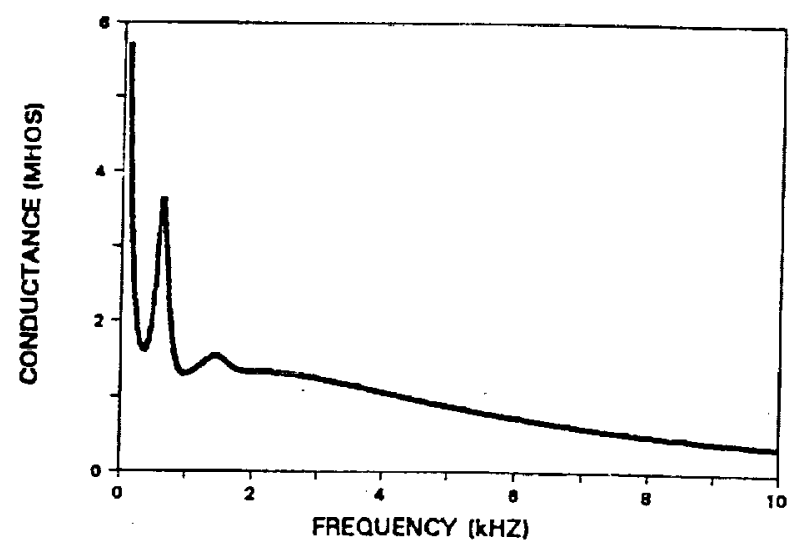

FIGURE 9A - CONDUCTANCE VS FREQUENCY $R=0.5$ OHMS, BCDUS AS SOURCE

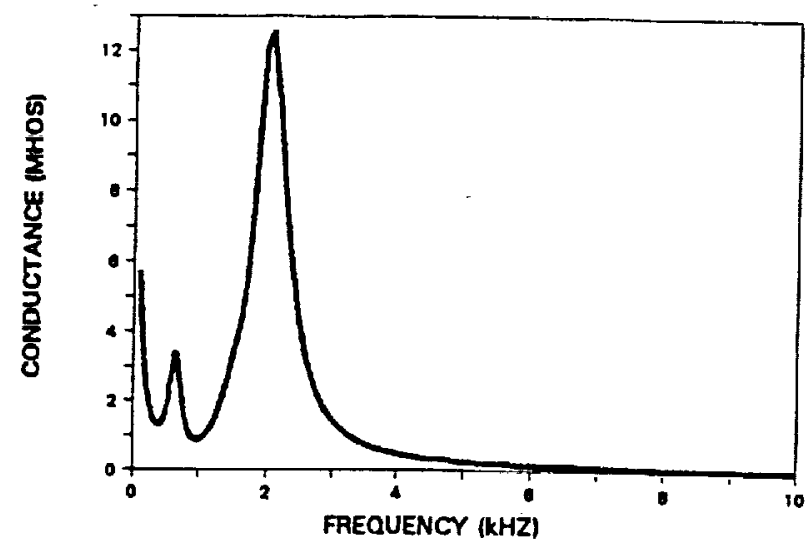

FIGURE 10A - CONDUCTANCE VS FREQUENCY $R=0.05$ OHMS, BCDUS AS SOURCE

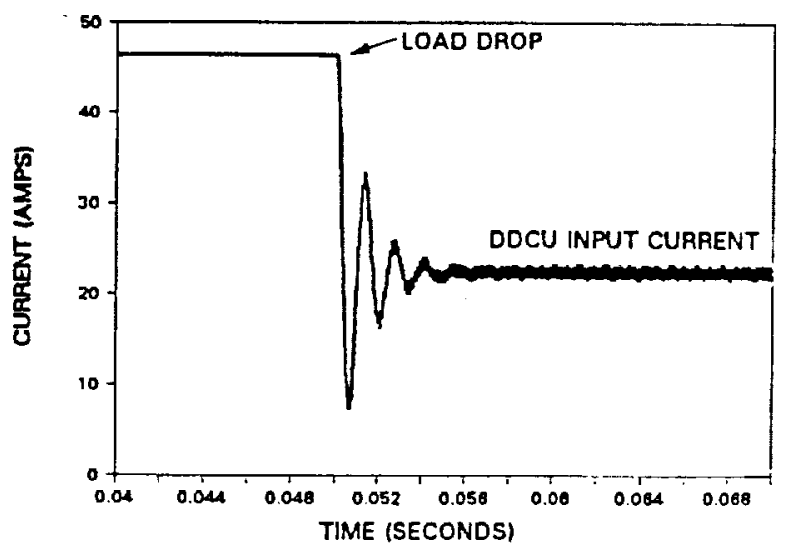

FIGURE 8B - DDCU 50\% LOAD DROP $R=0.05$ OHMS, SA \& SSU SOURCE

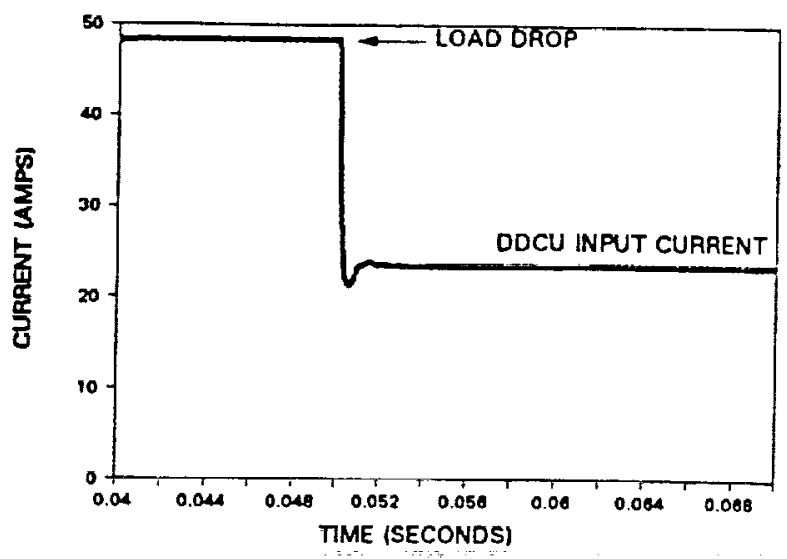

FIGURE 9B - DDCU 50\% LOAD DROP $R=0.5$ OHMS, BCDUs AS SOURCE

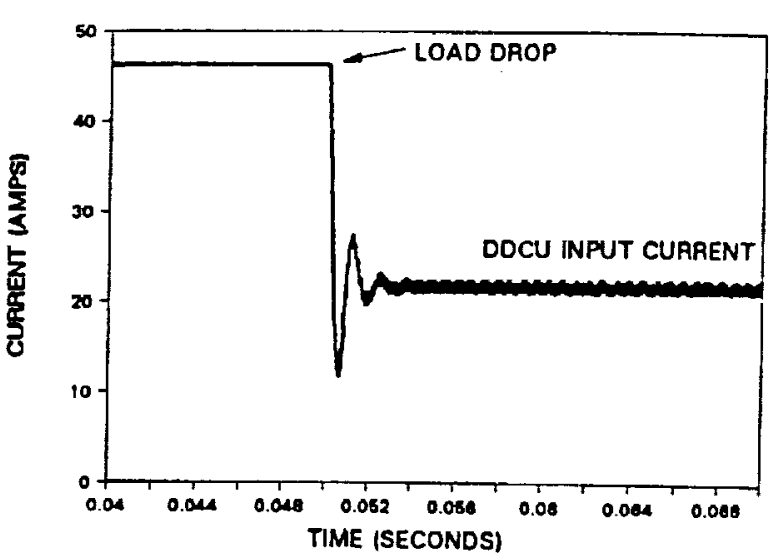

FIGURE 10B - DDCU 50\% LOAD DROP $R=0.05$ OHMS, BCDUS AS SOURCE 
Public reporting burden for this collection of inlormation is estimated to average 1 hour per response, including the time for reviewing instructions, searching existing data sources, gathering and maintaining the data needed, and completing and reviewing the collection of information. Send comments regarding this burden estimate or any other aspect of this

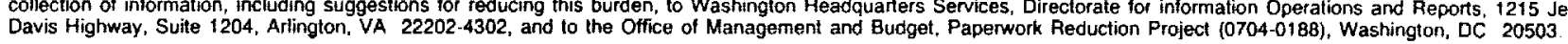

\begin{tabular}{|l|l|l|}
\hline 1. AGENCY USE ONLY (Leave blank) & $\begin{array}{r}\text { 2. REPORT DATE } \\
\text { August } 1992\end{array}$ & $\begin{array}{r}\text { 3. REPORT TYPE AND DATES COVERED } \\
\text { Technical Memorandum }\end{array}$ \\
\hline
\end{tabular}

\section{TITLE AND SUBTITLE}

EMTP Based Stability Analysis of Space Station Electric Power System in a Test Bed Environment

6. AUTHOR(S)

Narayan V. Dravid, Thomas J. Kacpura, and Andrew M. O'Connor

\section{PERFORMING ORGANIZATION NAME(S) AND ADDRESS(ES)}

National Aeronautics and Space Administration

Lewis Research Center

Cleveland, Ohio 44135-3191

9. SPONSORING/MONITORING AGENCY NAMES(S) AND ADDRESS(ES)

National Aeronautics and Space Administration

Washington, D.C. 20546-0001
5. FUNDING NUMBERS

WU $-474-42-10$

8. PERForming organization REPORT NUMBER

E-7288

10. SPONSORING/MONITORING AGENCY REPORT NUMBER

NASA TM-105845

\section{SUPPLEMENTARY NOTES}

Prepared for the 27/h Intersociety Encrgy Conversion Enginecring Conference cosponsored by the ANS, SAE, ACS, AIAA, ASME, and IEEE, San Diego, California, August 3-7, 1992. Narayan V. Dravid, NASA Lewis Rescarch Center, Cleveland, Ohio. Thomas J. Kacpura, Sverdrup Technology, Inc., Lewis Research Center Group, 200I Aerospace Parkway, Brook Park, Ohio 44142. Andrew M. O’Connor, Analytical Enginecring Corporation, 25111 Country Club Boulcvard, North Olmsted, Ohio 44070. Responsible person, Narayan V. Dravid, (216) 433-2733.

12a. DISTAIBUTION/AVAILABILITY STATEMENT

Unclassified - Unlimited

Subject Category 33

\section{ABSTRACT (Maximum 200 words)}

The Space Station Freedom Electric Power System (EPS) will convert solar energy into electric energy and distribute the same using an 'all dc', Power Management and Distribution (PMAD) System. Power conditioning devices (dc to dc converters) are needed to interconnect parts of this system operating at different nominal voltage levels. Operation of such devices could generate under damped oscillations (instability) under certain conditions. Criteria for instability are examined and verified for a single device. Suggested extension of the criteria to a system operation is examined by using the EMTP model of the PMAD DC test bed. Wherever possible, data from the test bed is compared with the modeling results.

\section{SUBJECT TERMS}

Space station power systems; System stability; Test bed computer simulation

A OF PAGES 8 16. PAICE CODE $\mathrm{AO} 2$

17. SECURITY CLASSIFICATION OF REPORT

Unclassified
18. SECURITY CLASSIFICATION OF THIS PAGE Unclassified
19. SECURTY CLASSIFICATION OF ABSTRACT Unclassified 